\title{
Study on Halide Ions Selectivity of Industrial Grade Anion Exchange Resin Auchlite A-378
}

\author{
P. U. Singare*, A. N. Patange \\ Department of Chemistry, Bhavan's College, Munshi Nagar, Andheri (West), Mumbai 400058, India \\ *E-mail address: pravinsingare@gmail.com
}

\begin{abstract}
The thermodynamic approach was applied to predict the trend selectivity of industrial grade anion exchange resin Auchlite A-378 in chloride form towards iodide and bromide ions in the solution. The study was conducted by performing the $\mathrm{Cl}^{-} / \mathrm{I}^{-}$and $\mathrm{Cl}^{-} / \mathrm{Br}^{-}$uni-univalent ion exchange reactions under gradually increasing temperature conditions. The thermodynamic equilibrium constants $K$ values were used to calculate the enthalpies of the two uni-univalent ion exchange reactions. It was observed that the $K$ values for $\mathrm{Cl}^{-} / \mathrm{I}^{-}$ion exchange reaction were higher than $\mathrm{Cl}^{-} / \mathrm{Br}^{-}$ exchange reaction under identical experimental conditions. Also the enthalpy values for the two uniunivalent ion exchange reactions were calculated as -39.51 and $-18.38 \mathrm{~kJ} / \mathrm{mol}$ respectively. The high $\mathrm{K}$ and low enthalpy values obtained for $\mathrm{Cl}^{-} / \mathrm{I}^{-}$ion exchange reaction is responsible for higher selectivity of the resin towards iodide ions as compared to that towards bromide ions, when both the ions are present in the same solution.
\end{abstract}

Keywords: selectivity; ion exchange reactions; halide ions; industrial grade resins; anion exchange resins; enthalpy; equilibrium constant; Auchlite A-378

\section{INTRODUCTION}

Ion exchange is the most appropriate and the most efficient method for the treatment of variety liquid industrial waste streams. With respect to economy and efficacy, ion exchange stands between the other two major liquid waste treatment processes of chemical precipitation and evaporation [1]. Chemical precipitation is often less expensive but is not always effective in treatment of industrial liquid waste. Evaporation method on the other hand may yield higher decontamination factors; but it is more costly than ion exchange. The development of new ion exchangers is narrowing the gap in decontamination factors between evaporation and ion exchange. Ion exchangers containing sulpho- and phospho- acidic groups and those containing tetra-ammonium basic groups are strong acidic and strong basic exchangers, respectively, whereas those containing phenolic and primary amino groups are weak acidic and weak basic exchangers, respectively. Exchangers with carboxy groups and tertiary amino groups take a medium position between strong and weak acidic and basic exchangers, respectively. Efforts to develop new organic ion exchangers for their specific industrial applications are continuing [2,3] and various aspects of ion exchange technologies have been continuously studied to improve the efficiency and economy of their application in 
various technological applications [4-9]. However, for proper selection of ion exchange resin, it is essential to have adequate knowledge regarding their physical and chemical properties, which forms the complementary part of resin characterization study [10-36]. Generally the selected ion exchange materials must be compatible with the chemical nature of the liquid waste such as $\mathrm{pH}$, type of ionic species present as well as the operating parameters, in particular temperature [37-40].

Hence in the present investigation thermodynamics of uni-univalent ion exchange reaction was studied to understand the selectivity behaviour of industrial grade anion exchange resin Auchlite A-378 towards the iodide and bromide ions in the solution.

\section{EXPERIMENTAL}

The ion exchange resin Auchlite A-378 as supplied by the manufacturer (Auchtel Products Ltd., Mumbai, India) was the weak base industrial grade anion exchangers in hydroxide form. The resin was having polystyrene matrix having tertiary ammonium functional group. The particle size of the resin was 0.3-1.2 mm, having moisture content of $48 \%$, operating $\mathrm{pH}$ range of $0-7$ and maximum operating temperature of $60.0{ }^{\circ} \mathrm{C}$. For present investigation, the resin grains of 30-40 mesh size were used. The soluble impurities of the resin were removed by repeated soxhlet extraction using water and occasionally with distilled methanol to remove non-polymerized organic impurities. In order to bring about complete conversion of resins in chloride form, the resins were conditioned with $10 \%$ potassium chloride solution in a conditioning column. The resins were washed with distilled deionised water until the washings were free from chloride ions. The resins in chloride form were air dried over $\mathrm{P}_{2} \mathrm{O}_{5}$ and used for further studies. The exchange capacity of the resin was experimentally determined by the standard method [41] using sodium nitrate and titrating against standard silver nitrate solution. Ion exchange resins $(0.500 \mathrm{~g})$ in chloride form were equilibrated with iodide ion solution of different concentrations at a constant temperature of $35.0^{\circ} \mathrm{C}$ for $3 \mathrm{~h}$. From the results of kinetics study reported earlier [10-36]; it was observed that this duration was adequate to attain the ion exchange equilibrium. After $3 \mathrm{~h}$, the iodide ion solutions in equilibrium with ion exchange resins in chloride form were analyzed for their chloride and iodide ion concentrations by potentiometric titration with standard $0.1 \mathrm{M}$ silver nitrate solution. From the results the equilibrium constant $K$ for the reaction

$$
\mathrm{R}-\mathrm{Cl}+\mathrm{I}^{-}{ }_{(\mathrm{aq})} \rightleftharpoons \mathrm{R}-\mathrm{I}+\mathrm{Cl}^{-}{ }_{(\mathrm{aq})}
$$

was determined at $35.0{ }^{\circ} \mathrm{C}$. The equilibrium constants $K$ for the above $\mathrm{Cl}^{-} / \mathrm{I}^{-}$system was determined for different temperatures in the range of $30.0{ }^{\circ} \mathrm{C}$ to $45.0{ }^{\circ} \mathrm{C}$.

Similar study was performed by equilibrating resins $(0.500 \mathrm{~g})$ in chloride form with bromide ion solution of different concentrations at a constant temperature of $35.0^{\circ} \mathrm{C}$ for $3 \mathrm{~h}$. After $3 \mathrm{~h}$, the bromide ion solutions in equilibrium with ion exchange resins in chloride form were analyzed for their chloride and bromide ion concentrations by potentiometric titration with standard $0.1 \mathrm{M}$ silver nitrate solution. From the results the equilibrium constant $K$ for the reaction

$$
\mathrm{R}-\mathrm{Cl}+\mathrm{Br}^{-}{ }_{(\mathrm{aq})} \rightleftharpoons \mathrm{R}-\mathrm{Br}+\mathrm{Cl}^{-}{ }_{(\mathrm{aq})}
$$

was determined at $35.0^{\circ} \mathrm{C}$. The equilibrium constants $K$ for the above $\mathrm{Cl}^{-} / \mathrm{Br}^{-}$system was determined for different temperatures in the range of $30.0^{\circ} \mathrm{C}$ to $45.0^{\circ} \mathrm{C}$. 
In the present study, a semi-micro burette having an accuracy of $0.02 \mathrm{~mL}$ was used in the titrations against silver nitrate solution. The titration readings were accurate to $\pm 0.02 \mathrm{~mL}$. Considering the magnitude of the titre values, the average equilibrium constants reported in the experiment are accurate to $\pm 3 \%$.

\section{RESULTS AND DISCUSSION}

The equilibrium constant for reactions 1 and 2 can be written as

$$
K=\frac{\mathrm{C}_{\mathrm{R}-\mathrm{X}} \cdot \mathrm{C}_{\mathrm{Cl}^{-}}}{\left(A-\mathrm{C}_{\mathrm{R}-\mathrm{X}}\right) \cdot \mathrm{C}_{\mathrm{X}^{-}}}
$$

here, $A$ is the ion exchange capacity of the resin and $\mathrm{X}^{-}$represents $\mathrm{I}^{-}$and $\mathrm{Br}^{-}$ions. For different concentrations of $\mathrm{X}^{-}$ions in solution at a given temperature, $K$ values were calculated and an average $K$ value for this set of experiments was found (Tables 1,2). Similar $K$ values were calculated for the $\mathrm{Cl}^{-} / \mathrm{I}^{-}$and $\mathrm{Cl}^{-} / \mathrm{Br}^{-}$system at different temperatures (Table 3 ).

Table 1. Equilibrium constant for the ion exchange reaction (1) using Auchlite A-378 resin. Amount of the ion exchange resin in chloride form $=0.500 \mathrm{~g}$, Ion exchange capacity $=0.74$ meq. $/ 0.5 \mathrm{~g}$, Temperature $=35.0^{\circ} \mathrm{C}$.

\begin{tabular}{|c|c|c|c|c|c|c|}
\hline System & $\begin{array}{c}\text { Initial } \\
\text { conc. } \\
\text { of iodide } \\
\text { ion (M) }\end{array}$ & $\begin{array}{c}\text { Final conc. } \\
\text { of iodide } \\
\text { ions (M) } \\
\mathrm{C}_{\mathrm{I}^{-}}\end{array}$ & $\begin{array}{c}\text { Change } \\
\text { in iodide } \\
\text { ion conc. }\end{array}$ & $\begin{array}{c}\text { Conc. of } \\
\mathrm{Cl}^{-} \text {ions } \\
\text { exchanged } \\
(\mathrm{M}) \\
\mathrm{C}_{\mathrm{Cl}^{-}}\end{array}$ & $\begin{array}{c}\text { Amount of } \\
\text { iodide ions } \\
\text { exchanged } \\
\text { on the resin } \\
\text { meq./0.5 } \mathrm{g} \\
\mathrm{C}_{\mathrm{RI}}\end{array}$ & $\begin{array}{c}\text { Equilibrium } \\
\text { constant } \\
(K) \\
\mathrm{x} 10^{-2}\end{array}$ \\
\hline 1 & 0.0100 & 0.0068 & 0.0032 & 0.0032 & 0.16 & 12.98 \\
\hline 2 & 0.0250 & 0.0208 & 0.0042 & 0.0042 & 0.21 & 8.00 \\
\hline 3 & 0.0490 & 0.0454 & 0.0036 & 0.0036 & 0.18 & 2.55 \\
\hline 4 & 0.0750 & 0.0720 & 0.0032 & 0.0032 & 0.16 & 1.23 \\
\hline 5 & 0.0960 & 0.0952 & 0.0008 & 0.0008 & 0.16 & 0.23 \\
\hline \multicolumn{7}{|c|}{ Average $K$} \\
\hline
\end{tabular}


Table 2. Equilibrium constant for the ion exchange reaction (2) using Auchlite A-378 resin. Amount of the ion exchange resin in chloride form $=0.500 \mathrm{~g}$, Ion exchange capacity $=0.74 \mathrm{meq} . / 0.5 \mathrm{~g}$, Temperature $=35.0^{\circ} \mathrm{C}$.

\begin{tabular}{|c|c|c|c|c|c|c|}
\hline System & $\begin{array}{c}\text { Initial } \\
\text { conc. } \\
\text { of bromide } \\
\text { ion (M) }\end{array}$ & $\begin{array}{c}\text { Final conc. } \\
\text { of bromide } \\
\text { ions (M) } \\
\mathrm{C}_{\mathrm{Br}^{-}}\end{array}$ & $\begin{array}{c}\text { Change } \\
\text { in bromide } \\
\text { ion conc. }\end{array}$ & $\begin{array}{c}\text { Conc. of } \\
\mathrm{Cl}^{-} \text {ions } \\
\text { exchanged } \\
(\mathrm{M}) \\
\mathrm{C}_{\mathrm{Cl}^{-}}\end{array}$ & $\begin{array}{c}\text { Amount of } \\
\text { bromide ions } \\
\text { exchanged } \\
\text { on the resin } \\
\text { meq./0.5 g } \\
\mathrm{C}_{\mathrm{RBr}}\end{array}$ & $\begin{array}{c}\text { Equilibrium } \\
\text { constant } \\
(K) \times 10^{-2}\end{array}$ \\
\hline 1 & 0.0100 & 0.0076 & 0.0024 & 0.0024 & 0.12 & 6.11 \\
\hline 2 & 0.0244 & 0.0224 & 0.0020 & 0.002 & 0.1 & 1.40 \\
\hline 3 & 0.0492 & 0.0476 & 0.0016 & 0.0016 & 0.08 & 0.41 \\
\hline 4 & 0.0736 & 0.0720 & 0.0016 & 0.0016 & 0.08 & 0.27 \\
\hline 5 & 0.0994 & 0.0986 & 0.0008 & 0.0008 & 0.16 & 0.22 \\
\hline \multicolumn{7}{|c|}{ Average $K$} \\
\hline
\end{tabular}

Table 3. Thermodynamics of ion exchange reactions using Auchlite A-378 ion exchange resin.

\begin{tabular}{|c|c|c|c|c|c|c|c|c|}
\hline Reactions & \multicolumn{3}{|c|}{1} & \multicolumn{3}{c|}{2} \\
\hline Temperature $\left({ }^{\circ} \mathrm{C}\right)$ & 30.0 & 35.0 & 40.0 & 45.0 & 30.0 & 35.0 & 40.0 & 45.0 \\
\hline $\begin{array}{c}\text { Equilibrium Constant } \\
(\boldsymbol{K}) \times 10^{-2}\end{array}$ & 9.01 & 5.00 & 4.73 & 4.05 & 2.16 & 1.68 & 1.17 & 1.10 \\
\hline Enthalpy $(\mathrm{kJ} / \mathrm{mol})$ & \multicolumn{3}{|c|}{-39.51} & \multicolumn{4}{c|}{-18.38} \\
\hline
\end{tabular}

The $\log K$ values were plotted against 1/T (in Kelvin), which gives a straight line graph (Figure 1) from the slope of this graph enthalpy values of the ion exchange reaction 1 and 2 were calculated (Table 3 ).

Bonner and Pruett [42] studied the temperature effect on uni-univalent exchanges involving some divalent ions. In all divalent exchanges, the equilibrium constant decreases with rise in temperature resulting in exothermic reactions. Similar results were obtained in the present investigation for Auchlite A-378 resins, during $\mathrm{Cl}^{-} / \mathrm{I}^{-}$and $\mathrm{Cl}^{-} / \mathrm{Br}^{-}$uni-univalent ion exchange reactions having the enthalpy values of -39.51 and $-18.38 \mathrm{~kJ} / \mathrm{mol}$ respectively (Table 3). The equilibrium constants $K$ for $\mathrm{Cl}^{-} / \mathrm{I}^{-}$ion exchange reaction were found to be higher than that for $\mathrm{Cl}^{-} / \mathrm{Br}^{-}$exchange under identical experimental conditions (Table 3). Similarly, the enthalpy value for $\mathrm{Cl}^{-} / \mathrm{I}^{-}$ion exchange reaction was lower than that calculated for $\mathrm{Cl}^{-} / \mathrm{Br}^{-}$ion exchange reaction. The relatively high $K$ and low enthalpy values obtained for $\mathrm{Cl}^{-} / \mathrm{I}^{-}$ion exchange reaction indicate higher selectivity of the resin towards iodide ions as compared to that towards bromide ions, when both the ions are present in the same solution [43-44]. 


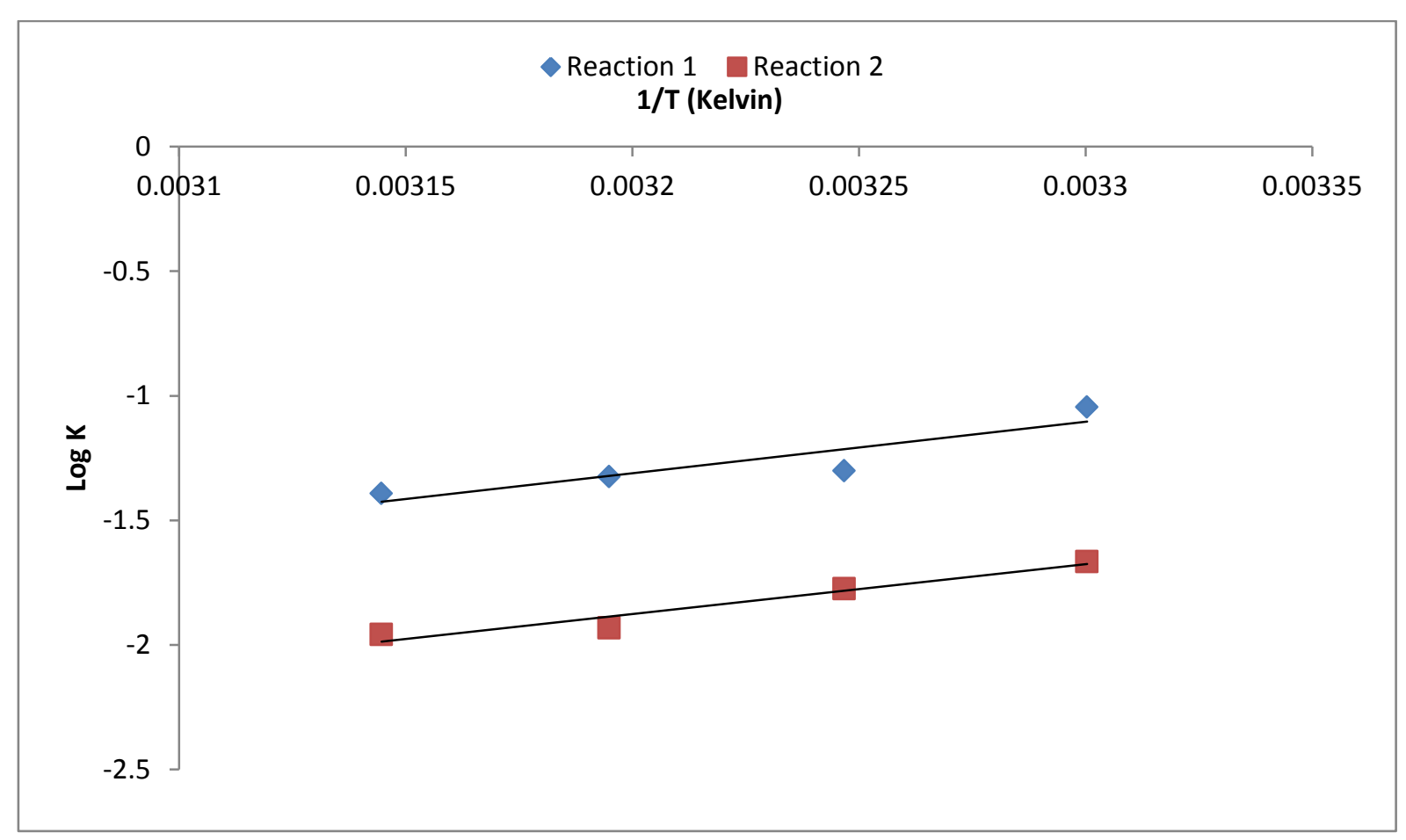

Figure 1. Effect of temperature on equilibrium constant of uni-univalent ion exchange reactions performed by using Auchlite A-378 resins.

\section{CONCLUSION}

Ion exchange technology is widely being used for separation of particular ionic species in presence of other. The selection of suitable ion exchange material is still more critical when the process involves separation of two or more chemically same ionic species in the solution. Under such critical conditions the present experimental technique will be useful in deciding about the selection of suitable ion exchange material. The technique used here can be extended further to standardise the process parameters in order to bring about the efficient separation of the desired ionic species from the solution.

\section{References}

[1] Application of Ion Exchange Processes For the Treatment of Radioactive Waste and Management of Spent Ion Exchangers, Technical Reports Series No. 408, International Atomic Energy Agency, Vienna, 2002.

[2] Tomoi M., Yamaguchi K., Ando R., Kantake Y., Aosaki Y., Kubota H., J. Appl. Poly. Sci. 64(6) (1997) 1161-1167.

[3] Zhu L., Liu Y., Chen J., Ind. Eng. Chem. Res. 48(7) (2009) 3261-3267.

[4] Samanta S. K., Ramaswamy M., Misra, B. M., Sep. Sci. Technol. 27 (1992) 255-267.

[5] Samanta, S.K., Theyyunni, T.K., Misra, B.M., J. Nucl. Sci. Technol. 32 (1995) 425-429. 
[6] Kumaresan, R., Sabharwal, K. N., Srinivasan, T. G., Vasudeva Rao, P. R., Dhekane, G., Solvent Extraction and Ion Exchange 24(4) (2006) 589-602.

[7] Deborah, L. S., Nazila, K., Douglas, B.K., James, A. D., Geochemical Transactions 14 (2013) 1.

[8] Singare, P.U., Lokhande, R.S., Madyal, R.S., Open Journal of Physical Chemistry 1(2) (2011) 45-54.

[9] Singare, P.U., Lokhande, R.S., Madyal, R.S., Rus. J. Gen. Chem. 80(3) (2010) 527-532.

[10] Singare, P.U., Diffusion Fundamentals Online Journal 19(4) (2013) 1-21.

[11] Singare, P.U., Int. J. Nucl. Energy Sci. and Technol. 8(2) (2014) 157-170.

[12] Singare, P.U., J. Nucl. Energy Science and Power Generation Technology 2(2) (2013) $1-6$.

[13] Singare, P.U., International Letters of Chemistry, Physics and Astronomy, 13 (2013) 37-49.

[14] Singare, P.U., International Letters of Chemistry, Physics and Astronomy, 13 (2013) 50-62.

[15] Singare, P.U., International Letters of Chemistry, Physics and Astronomy, 13 (2013) 63-76

[16] Singare, P.U., International Letters of Chemistry, Physics and Astronomy, 13 (2013) 77-89

[17] Singare, P.U., International Letters of Chemistry, Physics and Astronomy, 12 (2013) $1-13$

[18] Singare, P.U., International Letters of Chemistry, Physics and Astronomy, 12 (2013) $14-27$

[19] Singare, P.U., International Letters of Chemistry, Physics and Astronomy, 6 (2013) $1-5$.

[20] Singare, P.U., Inter. J. Materials and Chemistry, 2(4) (2012) 151-157.

[21] Singare, P.U., Phys. Chem., 2(4) (2012) 48-55.

[22] Singare, P.U., Science and Technology, 2(5) (2012) 135-141.

[23] Singare, P.U., American J. Fluid Dynamics, 2(5) (2012) 71-77.

[24] Singare, P.U., American J. Chem., 2(5), 263-270 (2012).

[25] Singare, P.U., Int. J. Composite Materials, 2(6) (2012) 119-126.

[26] Singare, P.U., J. Nuclear and Particle Physics, 2(5) (2012) 119-125.

[27] Singare, P.U., Frontiers in Science, 2(6) (2012) 235-242.

[28] Singare, P.U., Advances in Anal. Chem., 2(5) (2012) 53-59.

[29] Singare, P.U., American J. Poly. Sci., 2(5) (2012) 115-121.

[30] Singare, P.U., Phys. Chem., 2(3) (2012) 37-42.

[31] Singare, P.U., Journal of Radioanalytical and Nuclear Chemistry, 299 (2014) 591-598. 
[32] Singare, P.U., Nuclear Engineering and Technology, 46(1) (2014) 93-100.

[33] Singare, P.U., Journal of Nuclear Engineering \& Technology, 4(1) (2014) 13-24.

[34] Singare, P.U., Journal of Nuclear Engineering \& Technology, 4(1) (2014) 1-12.

[35] Singare, P.U., Journal of Nuclear Engineering \& Technology, 3(2) (2013) 14-24.

[36] Singare, P.U., Journal of Nuclear Engineering \& Technology, 3(3) (2013) 1-11.

[37] Heumann, K.G., Baier, K., Chromatographia, 15(11) (1982) 701-703.

[38] Adachi, S., Mizuno, T., Matsuno, R., J. Chromatogr. A, 708 (1995) 177-183.

[39] Shuji, A., Takcshi, M., Ryuichi, M., Biosci. Biotechnol. Biochem., 60(2) (1999) 338-340.

[40] Cortina, J. L., Warshawsky, A., Kahana, N., Kampel, V., Sampaio, C. H., Kautzman, R.M., Reactive and Functional Polymers, 54(1-3) (2003) 25-35.

[41] Jeffery, G. H., Basset, J., Mendham, J., Denney, R. C., Ion Exchange, in Vogel's Textbook of Quantitative Chemical Analysis, 5th Ed., ELBS, Longman Scientific and Technical, England, 1989, pp. 208.

[42] Bonner, O.D., Pruett, R.R., J. Phys. Chem., 63 (1959) 1420.

[43] P. U. Singare, A. N. Patange, International Letters of Chemistry, Physics and Astronomy 6 (2014) 1-7.

[44] P. U. Singare, A. N. Patange, International Letters of Chemistry, Physics and Astronomy 6 (2014) 8-15. 